\title{
A study of the effects of dietary gum arabic in the rat
}

\author{
BY ALASDAIR H. MCLEAN ROSS ${ }^{1 *}$, MARTIN A. EASTWOOD ${ }^{1 \dagger}$, \\ WILLIAM G. BR YDON ${ }^{1}$, ANTHONY BUSUTTIL ${ }^{2}$ AND LINDA \\ F. MCKAY ${ }^{1}$ \\ 1 Wolfson Gastrointestinal Laboratory, Gastrointestinal Unit and \\ 2 Department of Pathology, Western General Hospital, Edinburgh EH4 $2 \mathrm{XU}$
}

\author{
AND DOUGLAS M. W. ANDERSON
}

Department of Chemistry, King's Buildings, University of Edinburgh, Edinburgh EH9 3JJ

\section{(Received 7 February 1983 - Accepted 25 July 1983)}

1. Gum arabic (GA) is a water-soluble polysaccharide (molecular weight approximately 850000 ) containing rhamnose, arabinose, glucuronic acid and galactose.

2. The metabolism of GA has been studied in the rat. Adult male Wistar rats were given GA incorporated into either an Oxoid breeders (OB) diet or an elemental (Elem) diet.

3. Intestinal contents were examined for precipitable GA using acidified ethanol. GA was found from stomach to small intestine but not in the caecum, colon or rectum.

4. Caecal excision and restoration of intestinal continuity resulted in GA recovery from stomach to rectum.

5. Excreted methane, hydrogen and volatile fatty acids (VFA) were measured as indicators of bacterial activity in the caecum and colon. Methane excretion increased on the $\mathrm{OB}+\mathrm{GA}$ diet and $\mathrm{H}_{2}$ concentrations remained unaltered. The Elem diet abolished gas production. When the animals were given the Elem $+\mathrm{GA}$ diet, $\mathrm{H}_{2}$ and methane were only produced after $28 \mathrm{~d}$. Faecal VFA increased with increasing GA intake, acetate concentration increased and butyrate concentration decreased with increasing GA dosage. Significant decreases in concentrations of VFA were found from caecum to left colon and from left colon to faeces.

6. It can be concluded that GA degradation occurs in the caecum and is associated with increased methane excretion, increased VFA concentrations and changes in the proportions of various VFA in the faeces.

Insufficient is known of the metabolism of fibre in the colon. It has been suggested that the fibre affects stool weight either directly (Kirwan et al. 1974) or by bacterial mass (Stephen \& Cummings, 1980) or by volatile fatty acids (VFA) derived therefrom (Hellendoorn, 1978). The variety of fibre sources makes studies difficult. In the present work we have studied a chemically well-characterized fibre isolate, gum arabic (GA), which is widely used in the food industry (Anderson et al. 1966). GA is water soluble and as such is likely to be broken down by bacteria. It forms a white precipitate with acidic ethanol and can be identified in gut contents. GA was fed to rats in two diets and aspects of caecal metabolic activity were measured. Such a system or model is readily repeatable and could be used to enable a variety of other fibres to be studied.

\section{MATERIALS AND METHODS}

Albino Wistar male rats were purchased either from Messrs Bantin \& Kingman, Kingston upon Hull, or from the animal facilities at the University of Edinburgh, Western General Hospital. In general, 200-300-g rats were used, housed with up to three rats in each cage and kept at an ambient temperature of between 20 and $21^{\circ}$. The light cycle used was $12 \mathrm{~h}$ on during the day and $12 \mathrm{~h}$ off at night.

* Present address: Ward 9, Royal Infirmary, Edinburgh.

† For reprints. 
Before the experiment the animals were fed for at least 1 month on a standard autoclaved Spratts (Spillers) small animal diet before being exposed to one of two diets. The first was a reconstituted diet which allowed the ready incorporation of gum arabic (GA) into pellet form. This diet was based on an Oxoid breeders (OB) diet $(12 \mathrm{MJ} / \mathrm{kg}$ ) (Oxoid Limited, Basingstoke) chosen for high protein content in order to minimize the nutritional deficiency caused by adding relatively large proportions of GA to the diet. Pellets of the OB diet were milled to a powder and GA was added at $25,50,100$ and $200 \mathrm{~g} / \mathrm{kg}$ as required. Water was added to make a thick paste which was extruded into rolls and dried on stainless-steel trays at $70-75^{\circ}$.

The other diet used was a low-residue, nutritionally-complete elemental (Elem) diet into which GA could be incorporated up to a concentration of $130 \mathrm{~g} / \mathrm{kg}$ dry weight. $240 \mathrm{~g}$ Flexical powder (Mead Johnston Laboratories, Slough) $(16.9 \mathrm{MJ} / \mathrm{kg}$ ) and $30 \mathrm{~g}$ gelatin were added to $600 \mathrm{ml}$ solution containing $40 \mathrm{~g}$ GA. The mixture was incorporated into moulds and allowed to set. The energy provision of the total dry material (Flexical, gelatin and GA) was $13.9 \mathrm{MJ} / \mathrm{kg}$.

Diets were fed to the animals $a d l i b$. or in measured amounts when necessary. Scattering was not a significant problem with the reconstituted diet, but scattering of the Elem diet made estimation of intake less accurate.

The GA used was taken from batches used in normal confectionery production (Rowntree Mackintosh Ltd, York) and conformed in all respects to the British Pharmacopoeia specification.

\section{Caecal excision procedure}

After an overnight fast rats were anaesthetized with diethyl ether by inhalation. A laparotomy was carried out through a vertical midline incision and the caecum exteriorized. After ligation of its vascular supply the caecum was excised and an end-to-end ileo-colic anastomosis fashioned using nylon sutures (5.0). The abdomen was closed with a nylon suture (4.0) and skin clips.

After surgery, rats were administered water for $48 \mathrm{~h}$ only and were thereafter weaned on to a pelleted diet over a further period of $48 \mathrm{~h}$.

A convalescent period of 1 month from the time of operation was allowed before conducting experiments on these animals. At the end of this time interval bowel function had returned to near normal judged by stool frequency and consistency.

\section{Sample collection}

Faeces were collected from animals housed in broad-spaced, gridded cages to minimize the possibility of coprophagy. Collections were over a $24 \mathrm{~h}$ period except from animals on a diet for which 3-4 d collections were employed, each $24 \mathrm{~h}$ portion of faeces being collected separately. Animals were killed by a combination of diethyl ether anaesthesia and cervical dislocation before abdominal evisceration. Stomach, small bowel, caecum and distal colon were isolated immediately and their contents evacuated into plastic containers. After harvesting, enteric contents and faeces were weighed, had their $\mathrm{pH}$ adjusted to $\mathrm{pH} 8.0$ and were then deep-frozen. Subsequently, they were freeze-dried in a Chemlab SB4 laboratory freeze-drier. Fresh samples were used for GA recovery experiments.

Intestinal contents were always collected in the morning to ensure maximal and constant intestinal filling after overnight feeding.

\section{Hydrogen and methane sampling}

Production of methane and $\mathrm{H}_{2}$ was estimated from the change in gas composition of the closed chamber $(300 \times 200 \times 200 \mathrm{~mm})$ containing a single animal for a period of $15 \mathrm{~min}$. The excretion rate was calculated from the concentration of test gas in the chamber (121) minus 
the volume of the rat, specific gravity $1 \cdot 0$. Background room air samples were taken before and after each set of animal measurements. Rats were always tested at the same time of day to eliminate any variations which might be attributed to time of food ingestion.

\section{Analytical procedures}

GA in aqueous solution was precipitated by addition of 4 vol ethanol, previously adjusted to be $0.1 \mathrm{M}$ with respect to hydrochloric acid. When intestinal contents were examined, water was added to dilute the contents $(1: 1, \mathrm{v} / \mathrm{v})$ and the suspension was centrifuged at $9000 \mathrm{~g}$ for $20 \mathrm{~min}$ to remove suspended mucoid or proteinaceous material before precipitation of GA with the acidified ethanol. VFA were measured using freeze-dried samples (Spiller et al. 1980). The method used to measure $\mathrm{H}_{2}$ and methane was that of Tadesse et al. (1979).

All results were analysed as mean values and standard deviations and compared using Student's unpaired $t$ test.

\section{RESULTS}

The effect of feeding GA on rat weight, caecal content weight and stool weight was examined in two dietary situations. Male Wistar rats were given either the OB diet for 2 weeks or the $\mathrm{OB}+100 \mathrm{~g} \mathrm{GA} / \mathrm{kg}$ diet for 2 weeks. Alternatively they were given the Elem or Elem $+130 \mathrm{~g} \mathrm{GA} / \mathrm{kg}$ diet for 2 weeks. The animal weight, the caecal contents weight expressed per kg body-weight and faecal dry-weight are shown in Table 1. Starting weights (g) of the rats given the four diets were (mean with SD): OB $422(17.5), \mathrm{OB}+100 \mathrm{~g} \mathrm{GA} / \mathrm{kg}$ $443(21 \cdot 8)$, Elem $313(18 \cdot 0)$, Elem $+130 \mathrm{~g} \mathrm{GA} / \mathrm{kg} 297(17 \cdot 0)$. The effect of GA in both the $\mathrm{OB}$ and Elem diets significantly increased both caecal contents and faecal weight. The dry weights of caecal contents on Elem and Elem + GA diets were 0.49 and $2.6 \mathrm{~g}$ respectively ( 870 and $830 \mathrm{~g}$ water $/ \mathrm{kg}$ respectively).

\section{The detection of precipitable $G A$ in the intestine of the rat}

The intestinal contents of the rats given GA were examined to determine the presence of any GA at various points along the gut, in order to determine the site of GA breakdown.

Male Wistar rats ( 3 months old, weighing approximately $350 \mathrm{~g}$ ) were given the $\mathrm{OB}$ diet alone or the $\mathrm{OB}+200 \mathrm{~g} \mathrm{GA} / \mathrm{kg}$ diet $a d$ lib. for 4 weeks. The faeces passed in the $24 \mathrm{~h}$ period before killing were collected. After $a d$ lib. overnight feeding, rats were killed and the intestinal contents from the stomach to distal colon were collected.

In animals given the $\mathrm{OB}+\mathrm{GA}$ diet, a white flocculent precipitate typical of GA was found in the stomach and small intestinal contents but this could not be detected in caecal or distal colonic contents or in the faeces. Although no typical precipitate was obtained from the distal intestinal contents, some precipitation of a gelatinous nature occurred. In animals given the control diet, $\mathrm{OB}$, no precipitate typical of GA was obtained anywhere along the intestine.

The effect of caecal excision on the detection of $G A$ in the gastrointestinal contents Three male adult Wistar rats were subjected to surgical excision of the caecum. After 2 months the $\mathrm{OB}+200 \mathrm{~g} \mathrm{GA} / \mathrm{kg}$ diet was offered $a d$ lib. for 2 weeks. Animals were then killed and intestinal contents collected and subjected to acidic ethanolic precipitation. During the period of GA feeding, the animals initially developed diarrhoea which later returned to a stool which was looser and less well formed than on the control diet. At autopsy, precipitable GA was detected in the stomach and the small intestine in animals with an intact gastrointestinal tract. In the animals where the caecum was removed, GA was detected along the whole length of the gastrointestinal tract and also in the faeces. There was no GA in faeces from animals with an intact gastrointestinal tract. 
Table 1. Effects of feeding Oxoid breeders $(O B)$ diet and elemental (Elem) diet with and without added gum arabic $(G A)$ for $14 d$ on rat body-weight, relative weight of caecal contents and faecal dry weight

(Mean values and standard deviations for number of rats shown in parentheses)

\begin{tabular}{|c|c|c|c|c|c|c|}
\hline \multirow[b]{2}{*}{ Diet } & \multicolumn{2}{|c|}{$\begin{array}{l}\text { Body-wt } \\
\text { (g) }\end{array}$} & \multicolumn{2}{|c|}{$\begin{array}{c}\text { Wt of } \\
\text { caecal contents } \\
\text { (g/kg body-wt) }\end{array}$} & \multicolumn{2}{|c|}{$\begin{array}{l}\text { Faecal dry wt } \\
\quad(\mathrm{g} / 24 \mathrm{~h})\end{array}$} \\
\hline & Mean & SD & Mean & SD & Mean & SD \\
\hline \multicolumn{7}{|l|}{$\mathrm{OB}$} \\
\hline Without GA (10) & 443 & 22 & $23^{* * *}$ & 3.0 & $5 \cdot 9^{* *}$ & 1.8 \\
\hline With $100 \mathrm{~g} \mathrm{GA} / \mathrm{kg}(10)$ & 449 & 26 & $32^{* * *}$ & 1.0 & $7 \cdot 8^{* *}$ & $1 \cdot 1$ \\
\hline \multicolumn{7}{|l|}{ Elem } \\
\hline Without GA (9) & 330 & 13 & $12^{* * *}$ & 3.0 & $0.7^{*}$ & $0 \cdot 2$ \\
\hline With 130 g GA/kg (9) & 311 & 9 & $49^{* * * *}$ & 11 & $1.0^{*}$ & 0.3 \\
\hline
\end{tabular}

Common superscripts indicate a significant difference between the two mean values for each diet with and without GA: ${ }^{*} P<0.02,{ }^{* *} P<0.0025,{ }^{* * *} P<0.001$.

\section{$H_{2}$ and methane production during $G A$ administration to rats}

Male albino Wistar rats, 3 months old, were fed ad lib. OB $+200 \mathrm{~g} \mathrm{GA} / \mathrm{kg}$ or Elem $+130 \mathrm{~g}$ $\mathrm{GA} / \mathrm{kg}$ for a period of $28 \mathrm{~d}$. At 3 months old all these rats produce methane and $\mathrm{H}_{2}$.

Gas samples were obtained at the start of the study from the animals on the unsupplemented diet and 2 and 4 weeks after starting the test diet.

Animals on the OB control diet showed (Table 2) a decrease in $\mathrm{H}_{2}$ production at $28 \mathrm{~d}$ compared with the start of the study $(P<0.02)$. There were no significant changes in methane production. Rats given an $\mathrm{OB}+200 \mathrm{~g} \mathrm{GA} / \mathrm{kg}$ diet showed an increase in methane excretion after 14 and $28 \mathrm{~d}$, the increase at $28 \mathrm{~d}$ being highly significant $(P<0.001$; paired Student's $t$ test). After $28 \mathrm{~d}$ there was a decrease in $\mathrm{H}_{2}$ excretion $(P<0.02)$ compared with the start of the study. $\mathrm{H}_{2}$ and methane production could not be detected in animals given an unsupplemented Elem diet at both 14 and $28 \mathrm{~d}$. In the group treated with an Elem diet with $\mathrm{GA}$ supplement, methane and $\mathrm{H}_{2}$ excretions were undetectable at $14 \mathrm{~d}$, but were detectable at $28 \mathrm{~d}$ in amounts not significantly different from control values.

Rats which had previously had caecal excisions were tested for gas excretion 2 months after surgery whilst on the $\mathrm{OB}$ diet alone or $\mathrm{OB}+200 \mathrm{~g} \mathrm{GA} / \mathrm{kg}$ diet. No rats produced methane after caecal excision. Only one animal produced considerable quantities of $\mathbf{H}_{2}$ whilst on the $\mathrm{OB}$ diet and $\mathrm{OB}+200 \mathrm{~g} \mathrm{GA} / \mathrm{kg}$ diet. At post mortem, this animal showed a subacute small intestinal obstruction at the site of the ileo-colic anastomosis.

\section{The pattern of faecal $V F A$ in rats given increasing quantities of $G A$}

Male albino Wistar rats were given the $\mathrm{OB}$ diet containing $\mathrm{GA}$ in various concentrations $(0,50,100$ and $200 \mathrm{~g} / \mathrm{kg})$ ad lib. for $28 \mathrm{~d}$.

Fig. 1 illustrates the concentration of total VFA in excreted faeces in each treatment group. Although a linear relationship $(r 0.61 ; P<0.01)$ existed between the GA ingested and total VFA concentration in the faeces, differences in concentration between control and GA-treated animals only existed in the animals given $100 \mathrm{~g} \mathrm{GA} / \mathrm{kg}$ diet $(6.9 \mathrm{~g} \mathrm{GA}$ ingested $/ \mathrm{kg}$ body-weight per $24 \mathrm{~h})(P<0.05)$. Table 3 demonstrates the percentage of total faecal VFA concentration contributed by butyrate and acetate with increasing concentration of GA; butyrate decreased while acetate increased as a proportion of the total VFA 
Table 2. Effect of feeding Oxoid breeders $(O B)$ diet and elemental (Elem) diet with and without added gum arabic $(G A)$ for 14 and 28 d on total methane and hydrogen excretion

(Mean values and standard deviations for number of rats shown in parentheses)

\begin{tabular}{|c|c|c|c|c|c|c|c|}
\hline \multirow{2}{*}{$\begin{array}{l}\text { Day of experiment... } \\
\text { Diet }\end{array}$} & \multicolumn{2}{|c|}{0} & \multicolumn{2}{|c|}{14} & \multicolumn{3}{|c|}{28} \\
\hline & Mean & SD & Mean & SD & Mean & & SD \\
\hline & \multicolumn{7}{|c|}{ Methane $(\mathrm{ml} / \mathrm{kg}$ per $\mathrm{h})$} \\
\hline \multicolumn{8}{|l|}{ OB } \\
\hline Without GA (5) & $0 \cdot 25$ & 0.22 & $0 \cdot 10$ & 0.01 & $0 \cdot 15$ & & 0.05 \\
\hline With $200 \mathrm{~g} \mathrm{GA} / \mathrm{kg}(6)$ & $0 \cdot 33^{* * *}$ & 0.14 & 0.95 & $0 \cdot 46$ & $0.98^{* * *}$ & & $0 \cdot 24$ \\
\hline \multicolumn{8}{|l|}{ Elem } \\
\hline Without GA (5) & 0.53 & 0.33 & & & & ND & \\
\hline \multirow[t]{2}{*}{ With $130 \mathrm{~g} \mathrm{GA} / \mathrm{kg}(6)$} & 0.65 & 0.32 & & & 0.25 & & 0.06 \\
\hline & \multicolumn{7}{|c|}{$\mathrm{H}_{2}(\mathrm{ml} / \mathrm{kg}$ per $\mathrm{h})$} \\
\hline \multicolumn{8}{|l|}{ OB } \\
\hline Without GA (5) & $0.69+\dagger$ & $0 \cdot 13$ & 0.29 & 0.23 & $0.36+\dagger$ & & 0.07 \\
\hline With $200 \mathrm{~g} \mathrm{GA} / \mathrm{kg}(6)$ & $0.86+\dagger$ & 0.28 & 0.82 & 0.58 & $0.42+\uparrow$ & & $0 \cdot 15$ \\
\hline \multicolumn{8}{|l|}{ Elem } \\
\hline Without GA (5) & $0 \cdot 21$ & $0 \cdot 17$ & & & & ND & \\
\hline With $130 \mathrm{~g} \mathrm{GA} / \mathrm{kg}(6)$ & 0.67 & 0.25 & & & 0.98 & & 0.36 \\
\hline
\end{tabular}

Common superscripts indicate a significant difference between mean values on the same diet regimen: †† $P<0.02$, **** $P<0.001$.

ND, not detected.

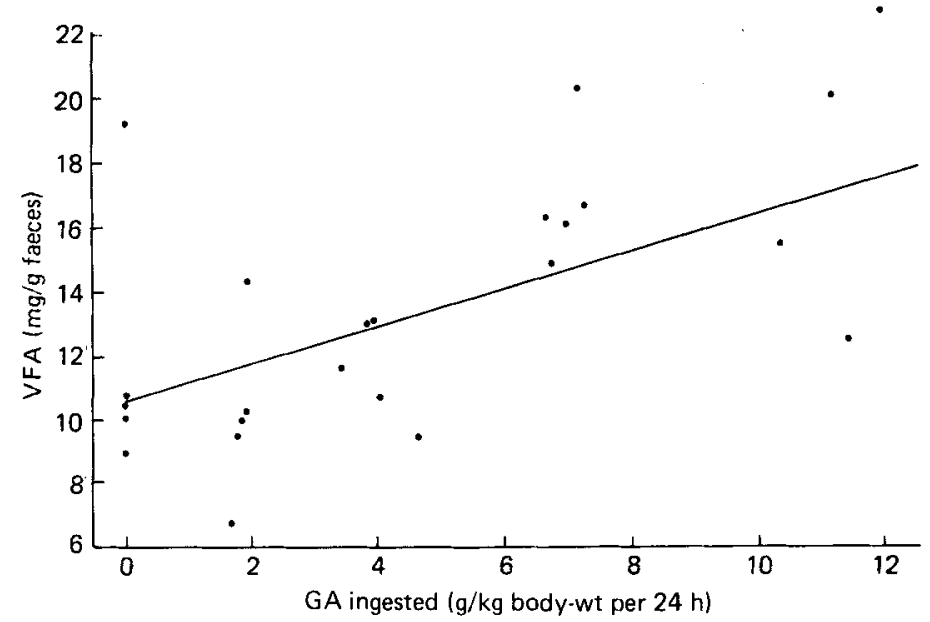

Fig. 1. The concentration of total volatile fatty acids (VFA) in faeces (mg VFA/g freeze-dried faeces) of rats (25) given gum arabic (GA) with Oxoid breeders diet.

concentration. These changes related linearly to the dose of ingested GA expressed either as $\mathrm{g} \mathrm{GA} / \mathrm{kg}$ diet $(r 0.96$ acetate, $r-0.89$ butyrate) or as $\mathrm{g} \mathrm{GA}$ ingested $/ \mathrm{kg}$ body-weight per $24 \mathrm{~h}$ ( $r 0.05$ acetate, $r-0.91$ butyrate). Propionate showed no significant changes with increasing concentrations of GA.

Significant decreases compared with control values in the proportion of butyrate in total VFA occurred in faeces from animals given $25,50,100$ and $200 \mathrm{~g} \mathrm{GA} / \mathrm{kg}+\mathrm{OB}$ diets 
Table 3. The percentage of total volatile fatty acids (VFA) concentrations represented by acetate and butyrate with increasing dose of gum arabic $(G A)$ in rats fed on Oxoid breeders diet (five rats in each group)

(Mean values and standard deviations)

\begin{tabular}{|c|c|c|c|c|c|c|c|c|c|c|}
\hline \multirow{2}{*}{$\begin{array}{l}\text { g GA/kg diet... } \\
\text { VFA }\end{array}$} & \multicolumn{2}{|c|}{0} & \multicolumn{2}{|c|}{25} & \multicolumn{2}{|c|}{50} & \multicolumn{2}{|c|}{100} & \multicolumn{2}{|c|}{200} \\
\hline & Mean & SD & Mean & SD & Mean & SD & Mean & SD & Mean & SD \\
\hline Acetate & 61.8 & $2 \cdot 5$ & 65.9 & $4 \cdot 0$ & 65.4 & 1.4 & 67.2 & $4 \cdot 1$ & 71.9 & 2.5 \\
\hline Butyrate & $23 \cdot 6$ & $2 \cdot 8$ & $17 \cdot 6$ & $3 \cdot 3$ & $19 \cdot 1$ & 1.5 & $16 \cdot 4$ & $2 \cdot 6$ & $13 \cdot 0$ & $2 \cdot 0$ \\
\hline
\end{tabular}

$(P<0.02,<0.02,<0.005,<0.001$ respectively). Significant increases in the proportion of acetate compared with control values were seen in faeces from animals given 50, 100 and $200 \mathrm{~g} \mathrm{GA} / \mathrm{kg}+\mathrm{OB}$ diets $(P<0.025,<0.05,<0.001$ respectively $)$.

The VFA concentrations of intestinal contents of rats given $G A$

Male adult albino Wistar rats, five animals in each group, were given the OB diet or $100 \mathrm{~g}$ $\mathrm{GA} / \mathrm{kg}+\mathrm{OB}$ diet for a period of 2 weeks. Fig. 2 demonstrates the typical profile of the VFA concentration in the rat intestine in animals given the OB diet. Little or no VFA were detectable in the small bowel content. The caecum contained the highest concentration of VFA, the concentration falling as the distal colon was reached. Excreted faeces showed concentrations lower than those in the left colon. The faecal VFA profile on the OB diet showed acetate, propionate and butyrate to be the main contributors with an inconsistent and minor contribution from valerate. This pattern did not alter when GA was added to the OB diet.

The caecal, colonic and faecal concentrations of total and individual VFA in rats given the $\mathrm{OB}+100 \mathrm{~g} \mathrm{GA} / \mathrm{kg}$ diet or the OB diet alone are shown in Tables 4 and 5 . A stepwise reduction in VFA concentration was seen from the caecum distally in both groups. Furthermore, in the GA-supplemented rats, intestinal contents had greater mean VFA concentrations at each site compared with controls. There was, however, much overlap of concentrations between the two groups and only in faeces did significant differences exist between control and $\mathrm{OB}+100 \mathrm{~g} \mathrm{GA} / \mathrm{kg}$ diet supplemented animals. The variability of faecal collection in rats and the ready emptying of the distal colon consequent on rat handling resulted in inconsistent and unreliable values. The rat caecum, however, assuming similar overnight feeding patterns, remained relatively constantly filled and thus VFA content could be more readily calculated and compared.

\section{The influence of the Elem diet on VFA production in the rat intestine}

Caecal VFA concentrations were higher $(P<0.05)$ in the Elem diet group of animals than in the GA + Elem diet-fed animals. When account was taken of the marked increased in caecal size in these animals, however, the GA-supplemented diets showed significantly more VFA content in the caecum $(P<0.05)$. Of interest was the appearance of isovaleric, valeric and isobutyric acids in the caecal contents of animals given the unsupplemented Elem diet.

\section{The influence of the caecum on the production of $V F A$}

The effect of caecal excision on VFA production has been studied in the present experiment. The concentration of VFA ( $\mathrm{mg} / \mathrm{g}$ faeces) showed a marked reduction in the animals 


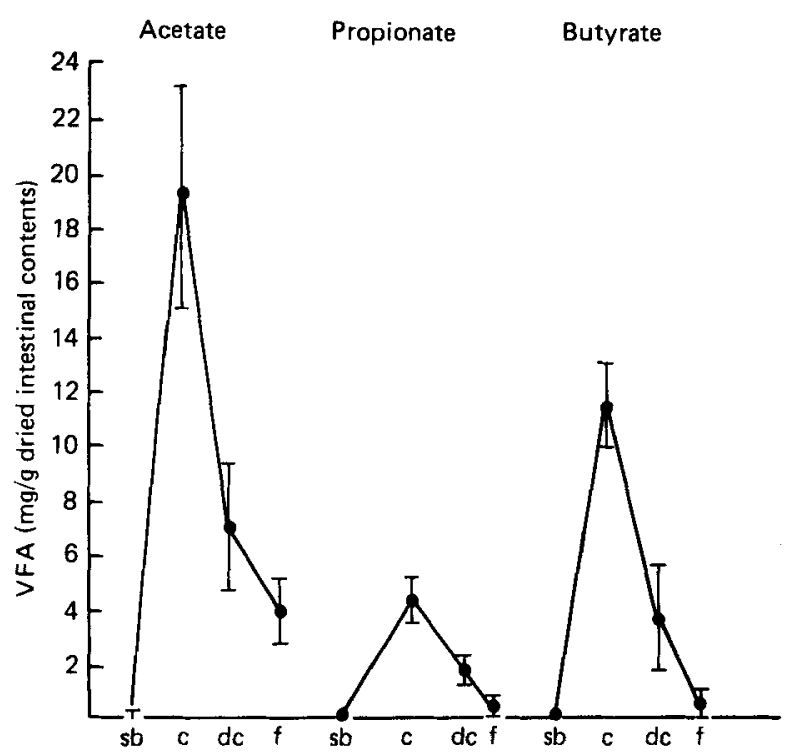

Fig. 2. Intestinal profile of the three principal volatile fatty acids (VFA) acetate, propionate and butyrate found in the intestinal contents $(\mathrm{mg} / \mathrm{g}$ ) of rats $(5)$ given Oxoid breeders diet. Points are mean values and standard deviations are represented by vertical bars. sb, Small bowel; c, caecum; dc, distal colon; f, faeces.

Table 4. Effect of feeding Oxoid breeders $(O B)$ diet and elemental $($ Elem $)$ diet with and without added gum arabic $(G A)$ for $14 d$ on the volatile fatty acid $(V F A)$ concentration of intestinal contents and faeces

(Mean values and standard deviations for number of rats shown in parentheses)

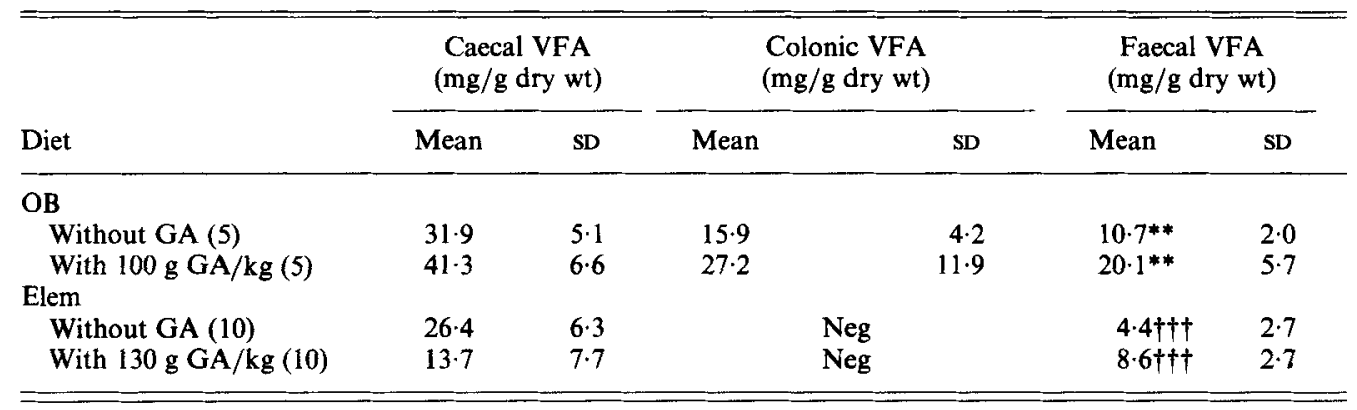

Common superscripts indicate a significant difference between the two mean values for each diet with and without GA: ** $P<0.01$, †† $P<0.005$.

Neg, colonic contents negligible and, therefore, unsuitable for VFA measurement.

subjected to caecal excision when compared with VFA concentration in the faeces of intact animals (normal 16, 4.2; after caecectomy 6.3, 1.3). It is likely that the absence of the caecal environment, in the main, resulted in the reduction of VFA concentration, although the loose and more frequent bowel motions produced on GA supplementation may have further contributed to this reduction. 
Table 5. Effect of feeding Oxoid breeders $(O B)$ diet and elemental (Elem) diet with and without gum arabic $(G A)$ for $14 d$ on individual volatile fatty acids $(V F A)^{*}$ concentrations in rat caecum

(Mean values and standard deviations for number of rats shown in parentheses)

\begin{tabular}{|c|c|c|c|c|c|c|c|c|}
\hline \multirow{2}{*}{$\begin{array}{l}\text { Diet... } \\
\text { VFA }\end{array}$} & \multicolumn{2}{|c|}{$\begin{array}{c}\text { OB } \\
\text { without } \\
\text { GA } \\
(5)\end{array}$} & \multicolumn{2}{|c|}{$\begin{array}{c}\text { OB with } \\
100 \mathrm{~g} \mathrm{GA} / \mathrm{kg} \\
(5)\end{array}$} & \multicolumn{2}{|c|}{$\begin{array}{c}\text { Elem } \\
\text { without } \\
\text { GA } \\
(10)\end{array}$} & \multicolumn{2}{|c|}{$\begin{array}{c}\text { Elem with } \\
130 \mathrm{~g} \mathrm{GA} / \mathrm{kg} \\
\text { (10) }\end{array}$} \\
\hline & Mean & SD & Mean & SD & Mean & SD & Mean & SD \\
\hline Acetate & 52.9 & 7.0 & $60 \cdot 5$ & $6 \cdot 5$ & 54.6 & $3 \cdot 0$ & $59 \cdot 6$ & $13 \cdot 7$ \\
\hline Propionate & \multirow{2}{*}{\multicolumn{2}{|c|}{$12 \cdot 5$}} & 12.4 & $2 \cdot 4$ & $18 \cdot 1$ & 0.9 & $20 \cdot 4$ & $5 \cdot 5$ \\
\hline Isobutyrate & & & \multicolumn{2}{|c|}{0} & $2 \cdot 1$ & $0 \cdot 2$ & \multicolumn{2}{|c|}{0} \\
\hline Butyrate & 34.6 & $6 \cdot 7$ & $27 \cdot 1$ & $4 \cdot 9$ & 13.8 & $2 \cdot 2$ & $17 \cdot 1$ & $6 \cdot 1$ \\
\hline Isovalerate & \multirow{2}{*}{\multicolumn{2}{|c|}{$\begin{array}{l}0 \\
0\end{array}$}} & \multicolumn{2}{|c|}{0} & 3.0 & $0 \cdot 3$ & \multicolumn{2}{|c|}{0} \\
\hline Valerate & & & & & 9.0 & 1.0 & & \\
\hline
\end{tabular}

* Results expressed as a percentage of total VFA concentration.

\section{DISCUSSION}

In the experiments described in the present paper aspects of GA metabolism were studied in the rat. GA has the property of being readily precipitable in vitro by acidic ethanol. This identifying property is somewhat complicated in practice as gut mucoproteins are also precipitated. However, the characteristic precipitate of GA, which is white, differs from the meagre brown precipitate of the mucoproteins.

GA is a complex acidic heteropolysaccharide of very high molecular weight (approximately $0.5-1.4 \times 10^{6}$ ) and is composed of a highly-branched array of galactose, arabinose, rhamnose and glucuronic acids. Uronic acid residues tend to occur in the periphery of this essentially globular molecular structure (Anderson et al. 1966). As GA dissolves in aqueous solution to the extent of approximately $400 \mathrm{~g} / 1$, it is used widely by the food industry as an additive or thickener.

The animals were given either a conventional complex mixed (OB) diet or a lowmolecular-weight elemental (Elem) diet. In the latter case the large intestine would receive GA free of nutrients as these would have been absorbed more proximally. The animals on the $\mathrm{OB}$ and the Elem diets grew at an equivalent rate both with and without GA which suggested that the animals were adequately fed and no complicating nutritional factor had been introduced. The proportion of the entire diet contributed by GA did not appear to cause any nutritional problems (Table 2 ).

As would be anticipated from the low-residue nature of an elemental diet, the weight of the caecal contents was lowest in these animals. There was a fourfold increase in the weight of the caecal contents when GA was added to the Elem diet. A limited increase occurred when GA was added to the $\mathrm{OB}$ diet. The stool weight of rats given the Elem + GA diet was substantially less than that of the animals given the $O B+G A$ diet. The changes in the weight of caecal contents were not reflected in the stool weight. This implied that events in the rat caecum may not necessarily relate directly to stool weight. The increase in the weight of caecal contents could result from either an increase in bacterial mass (Stephen \& Cummings, 1980) or the retention of water in the caecal contents or by an increase in residual GA in the caecum or a combination of these factors. No macroscopic or histological evidence of caecal wall hypertrophy was found on histological examination. The percentage weight of water in the caecum was 87 and 83 for the Elem and Elem + GA diets respectively. 
However, the methods used do not differentiate between free water and intracellular bacterial water. Bacterial mass was not measured; there are difficulties in this measurement whether diaminopimelic acid, DNA estimations or bacterial counts are used (Czerkawski, 1976). Such studies will constitute future experiments.

Precipitable GA was identified along the gastrointestinal tract as far as the terminal ileum, but none was found in the caecum. This suggests that metabolism of the GA is mediated by bacteria within the caecum. It is possible that the non-specific qualitative test of the insolubility of GA in acidified ethanol may not detect partially-degraded polysaccharide below a certain limiting molecular weight. In the animals where the caecum was resected, the precipitable GA was found along the length of the entire residual intestine. This suggests that in the absence of the bacterial mass resident in the caecum there is no degradation of GA.

The measurements of breath methane and $\mathrm{H}_{2}$ in the expired breath and VFA were indices of large intestine bacterial metabolic activity. All rats over the age of 3 months produce methane in their expired breath and $\mathrm{H}_{2}$ is excreted throughout their lifetime. Caecectomy abolished $\mathrm{H}_{2}$ and methane production except in one animal where there was a subacute intestinal obstruction. This ablation of gas production suggests that the caecum is the major site of bacterial activity; caecectomy results in loss of these bacteria and failure of GA breakdown. There was, however, diminished $\mathrm{H}_{2}$ and methane production on the Elem diet indicating that the low-residue nature of this regimen delivers less substrate for bacterial metabolic activity. When GA was added to the Elem diet there was a reappearance of $\mathbf{H}_{2}$ and methane in the expired breath but only when measured at $28 \mathrm{~d}$. This suggests that GA was being metabolized by the caecal bacteria only. The effect of adding GA to the $O B$ diet was to increase the production of methane and to decrease the $\mathrm{H}_{2}$ production. This shows that the metabolic fate of GA is in part dictated by the other constituents of the diet.

When GA was given with the OB diet there was an increase in caecal VFA concentrations, but when given with the Elem diet there was a decrease. This may be due to variation in production, bacterial utilization or caecal absorption. It does suggest, however, that the congeners, the other constituents of the diet, affect the mode in which the GA is metabolized. The Elem diet was associated with a wider VFA spectrum: isobutyrate, isovalerate and valerate were present in significant amounts. The effect of adding GA to the Elem diet was to increase fractionally the acetate content of the caecal contents; the butyrate concentration decreased and the minor VFA disappeared.

The total faecal VFA increased with the OB + GA diet which suggests that GA was metabolized to VFA. This was associated with an increase in the proportion of faecal acetate and a decrease in butyrate. Therefore GA was affecting metabolism in or absorption from the colon. It was shown previously that there are considerable concentrations of acetate in the portal blood of rats (Buckley \& Williamson, 1977). This suggests that bacterial metabolism within the large bowel provides acetate which may be a source of nutrition for the rat.

GA is an important polysaccharide particularly in confectionery, and as such it is a constituent of the human diet. It is unusual as a fibre type in that it is an isolated gum and not part of the cereal, fruit or vegetable type of fibre source. It is also characterized by being a water-soluble fibre and as such is distinct from the cereal-bran type of fibre. Experiments described in the present paper suggest that, given a method for identifying a fibre, the rat might be used to study the metabolism of that fibre. Whilst there are inherent problems in applying findings in the rat to man, results consistent with the results in this paper have been found in an experiment wherein GA has been fed to man (McLean Ross et al. 1983). 


\section{REFERENCES}

Anderson, D. M. W., Hirst, E. \& Stoddart, J. F. (1966). Journal of the Chemical Society Section C, $1959-1966$. Buckley, B. M. \& Williamson, D. H. (1977). Biochemical Journal 166, 539-545.

Czerkawski, J. W. (1976). Journal of the Science of Food and Agriculture, 27, 621-632.

Hellendoorn, E. W. (1978). In Topics in Dietary Fiber Research, pp. 127-168 [G. A. Spiller, editor]. New York: Plenum Press.

Kirwan, W. O., Smith, A. N., McConnell, A. A., Mitchell, W. D. \& Eastwood, M. A. (1974). British Medical Journal iv, 187-189.

McLean Ross, A. H., Eastwood, M. A., Anderson, J. R. \& Anderson, D. M. W. (1983). American Journal of Clinical Nutrition 37, 368-375.

Spiller, G. A., Chernoff, M. C., Hill, R. A., Gates, J. E., Nassar, J. J. \& Shipley, E. A. (1980). American Journal of Clinical Nutrition 33, 754-759.

Stephen, A.M. \& Cummings, J. H. (1980). Nature 284, 283-284.

Tadesse, K., Smith, A., Brydon, W. G. \& Eastwood, M. A. (1979). Journal of Chromatography 171, $416-418$. 